\title{
EDITOR'S REPORT
}

If life can be considered a process of casting suspicious glances over one's shoulder, editors have behind them issues and volumes that make the perception clearly visible. But how does one retrospect productively?

We recently decided to approach this question by collecting data, in a variety of categories, on all papers submitted to us. This Journal, it should be kept in mind, is somewhat unusual in at least two respects. First, we accept documents from any and all behavioral, social, and asocial scientists or significant others. Second, we are not at all interested in ritualistic research or precision parametric or nonparametric studies, unless they aim to solve a significant, real problem.

Some early results are in. They cover 238 pages (a little less than half the number we receive annually) submitted in a six-month period last year. Following are some random and disparate findings.

Authors: The prime contributors were psychologists $(32.8 \%)$, followed by psy- chiatrists $(28.2 \%)$, and social workers $(16.8 \%)$; authors of other disciplines, some of which we were unable to identify, accounted for the balance. The principal work settings of the authors were universities $(49.2 \%)$, clinics $(17.2 \%)$, and community agencies (13\%). Just over half

(Continued on Page 507)

\section{Erratum}

In "Mother-Child Interaction: A Comparison of Hyperactive, Learning Disabled, and Normal Boys," by Susan B. Campbell, published in the January 1975 issue of this Journal (Vol. 45, No. 1 , pp. 51-57), there is a typographical error in the final sentence on page 52 , which renders the sentence meaningless. The sentence should read as follows:

"In both groups, primary emotional, neurological, and sensory impairments were ruled out; no child was on medication."

\section{NOTICE}

\section{TO ORTHO MEMBERS, JOURNAL SUBSCRIBERS, AND OTHER READERS}

Beginning with Volume 46 (1976), this Journal will discontinue publication of its special March issue, devoted to 500-word digests of papers presented at the Annual Meeting of the American Orthopsychiatric Association.

This move is being made primarily to forestall the necessity of raising Journal subscription prices or Ortho membership dues. During the past year, publication costs-printing, mailing, and paper-have risen sharply. (Paper has been a particularly vexing problem; increases in cost have been matched by declines in quality and availability.) As a result, many journals and other publications have either raised subscription fees or altered format to achieve economies.

We remain reluctant to raise prices or to curtail publication of the original research, reviews, and program reports that constitute the main product and prime purpose of the Journal. Elimination of the Digest issue was decided on the basis of its being the least integral and most transitory aspect of the Journal.

Thus, the Journal reverts to a quarterly. Neither format nor content of the four regular Journal issues will be in any way affected by discontinuance of the Digest issue. As in the past, some of the papers presented at the Annual Meeting will be selected for publication in full in the Journal. Similarly, brief abstracts of Annual Meeting papers will continue to be printed in the Program of the Annual Meeting. 